\title{
FARELO DE TRIGO E COMPLEXO ENZIMÁTICO NA ALIMENTAÇÃO DE FRANGAS DE REPOSIÇÃO ${ }^{1}$
}

\author{
Wheat bran and enzymatic complex in laying hens feed
}

\author{
Daniel de Magalhães Araujo ${ }^{2}$, José Humberto Vilar da Silva ${ }^{3}$, José Anchieta de Araujo ${ }^{4}$, \\ Marcelo Luiz Gomes Ribeiro ${ }^{5}$, Leonardo Augusto Fonseca Pascoal ${ }^{6}$, Fernando Guilherme Perazzo Costa ${ }^{7}$
}

\begin{abstract}
RESUMO
Foram avaliados os efeitos da inclusão do farelo de trigo (FT) com e sem a suplementação da ração com um complexo enzimático (CE), composto de amilase, protease e celulase, sobre o desempenho de frangas semipesadas (15 semanas de idade) e seu efeito residual na produção de ovos. Foram utilizadas 288 frangas, distribuídas em delineamento inteiramente casualizado, em esquema fatorial 4X2, sendo quatro níveis de FT e dois níveis de um CE na ração: 0 (controle), 10, 20 e 30\% X suplementação com 0 ou $50 \mathrm{~g}$ de um CE/100 kg de ração, resultando em oito tratamentos, com seis repetições. Na fase de crescimento, o consumo de ração, o ganho de peso, a conversão alimentar e o peso vivo foram melhores para as aves que receberam as dietas isentas de FT. A adição do CE diminuiu o consumo de ração nas dietas com 0 e $30 \%$ de FT. Durante a fase de produção, o uso do CE na ração de recria sem FT aumentou o peso vivo das aves, mas reduziu no nível de $30 \%$ de FT. A produção de ovos diminuiu no nível de $20 \%$ de FT quando a dieta foi suplementada com o CE. As conversões alimentares no nível de $10 \%$ de FT foram semelhantes ao controle. Observou-se efeito quadrático do nível de FT sobre a conversão por massa de ovos, que foi melhor com $8,01 \%$. Portanto, recomenda-se até $8,01 \%$ de inclusão do farelo de trigo na ração de poedeiras semipesadas de 15 a 19 semanas de idade.
\end{abstract}

Termos para indexação: Alimento alternativo, enzimas exógenas, produção de ovos.

\begin{abstract}
This study was carried out with the aim of evaluating the effects of the inclusion of the wheat bran (WB) and the addition of an enzymatic complex (EC), amylase, protease and celullase contained, on the performance of semi-heavily pullets from 14 weeks of age and its residual effect on egg-production phase. 288 pullets were used, distributed in a completely randomized design in a factorial arrangment 4X2, being the following levels of WB in the ration: 0 (control), 10, 20 and $30 \%$ X 0 or $50 \mathrm{~g}$ of a EC/100 kg of diet, resulting in eight treatments, with six replicates of six birds. The EC contained the enzymes amylase, protease and celullase. In the growth phase, FI, WG, FC and LW showed better for the birds that received the diets without FT. The addition of the EC decreased the consumption in the diets with 0 and 30\% of WB. During the production phase, the use EC in the level $0 \%$ of WB increased LW of the birds, but it reduced in the level $30 \%$ of WB. The production of eggs fell in the level of $20 \%$ of WB when the diet was supllementing with EC. The feed conversion in the level of $10 \%$ of WB was similar to the control. Quadratic effect of the level of WB was observed on the feed egg-mass conversion, that was better with $8,01 \%$. Therefore, it is recommended up to $8.01 \%$ of inclusion of the wheat bran in the ration of semi-heavily pullets from 14 to 19 weeks of age.
\end{abstract}

Index terms: Alternative feedstuff, egg production, exogenous enzymes.

(Recebido em 4 de outubro de 2007 e aprovado em 31 de março de 2008)

\section{INTRODUÇÃO}

O uso de resíduos da agroindústria na alimentação das aves é importante para fortalecer a avicultura pelo provável impacto positivo na redução dos custos de produção. Além disto, como a região semi-árida brasileira apresenta baixa produção de milho (SILVA et al., 2002) e também não é tradicional produtora de soja, o sucesso ou fracasso da atividade avícola, nessa região, depende da variação dos preços internacionais e ainda dos custos com o transporte dessas matérias-primas às empresas avícolas .

\footnotetext{
${ }_{1}^{1}$ Parte da Dissertação de Mestrado do 1ํ Autor, Bolsista CAPES, apresentada ao Programa de Pós-Graduação em Zotecnia/CCA/UFPB, Areia - PB. 'Doutorando em Zootecnia - Departamento de Melhoramento Zootécnico e Nutrição Animal - Faculdade de Medicina Veterinária e Zootecnia/FMVZ Universidade Estadual Paulista/UNESP - Fazenda Experimental Lageado - Cx. P. 560 - 18618-000 - Botucatu, SP - danielzootecnista@yahoo.com.br Bolsista da FAPEAL.

3Doutor, Professor - Departamento de Agropecuária - Universidade Federal da Paraíba/UFPB - Rua Tancredo Neves, 144 - 58225-000 - Solanea, PB jvilar@cft.ufpb.br - Bolsista PQ/CNPq.

${ }^{4}$ Mestrando em Zootecnia - Universidade Federal da Paraíba/UFPB - Vila Acadêmica, Centro de Ciências Agrárias -58397-000 - Areia, PB anchietaaraujo@gmail.com - Bolsista CAPES.

${ }^{5}$ Doutor, Professor - Departamento de Agropecuária - Universidade Federal da Paraíba/UFPB - Rua Henrique Lucena, 26 - Centro - $58220-000$ Bananeiras, PB - marcelolgr@hotmail.com

${ }^{6}$ Zootecnista, Doutorando em Zootecnia - Departamento de Zootecnia - Faculdade de Ciências Agrárias e Veterinárias/FCAV - Universidade Estadual Paulista/UNESP - Travessa José Biondi, 1105, casa 02 - Jardim Nova Aparecida - 14883-382 - Jaboticabal, SP - pascoallaf@yahoo.com.br

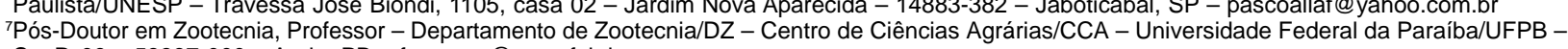
Cx. P. 09 - 58397-000 - Areia, PB - fperazzo@cca.ufpb.br
} 
O farelo de trigo (FT) é um subproduto tradicionalmente utilizado na formulação de rações de aves de postura nas indústrias de rações, entretanto, além de pioneiros, são recentes os dois únicos estudos dos seus efeitos sobre o desempenho dessas aves na literatura nacional. São eles os trabalhos de Araujo et al. (2008a,b).

De acordo com Beaugrand et al. (2004) o FT é o principal e mais abundante subproduto da moenda de grãos. Esse subproduto é formado por tecidos botânicos distintos, exteriores ao núcleo do trigo, como o pericarpo (película que recobre o grão), a testa (película que recobre a semente), a camada hialina e a aleurona, sendo, as duas últimas, partes externas do endosperma (EVERS \& MILLAR, 2002). O endosperma é composto por células com paredes celulares difíceis de fracionar. Entretanto, o processo de moenda permite o rompimento dessas paredes, liberando vários micronutrientes como o selênio e o ácido fólico ou fitoquímicos; como flavonóides e ácido fítico (HELSBY et al., 2000).

O trigo é considerado um ingrediente promotor do aumento da viscosidade intestinal pelo seu alto porcentual de polissacarídeos não-amídicos (PNA's) solúveis, como as arabinoxilans. As arabinoxilans do trigo causam uma inibição geral de digestão dos nutrientes, afetando a digestibilidade de carboidratos, gorduras e proteínas. Também pode resultar em um aumento da secreção de proteínas endógenas, derivadas do intestino, além da perda de células intestinais (BEDFORD \& PARTRIDGE, 2001). A estrutura física das paredes das células do endosperma desse grão também pode impedir o acesso das enzimas digestivas aos seus nutrientes (BEDFORD, 2000).

Dentre os efeitos prejudiciais dos PNA's estão a modificação do tempo de trânsito e da mucosa intestinal e a alteração da regulação hormonal pela variação na taxa de absorção dos nutrientes (BEDFORD \& PARTRIDGE, 2001). Como a maior parte dos fatores antinutricionais do trigo estão concentrados nas camadas exteriores, que no processo de moenda ficam contidos no farelo de trigo, esses efeitos podem ser mais intensos em aves alimentadas com esse subproduto.

Os PNA's são os principais substratos para fermentação bacteriana, particularmente no intestino grosso de animais monogástricos e também possuem características benéficas, por interagirem com a mucosa e a microflora, tendo um importante papel no controle da "saúde intestinal" (MONTAGNE et al., 2003). Além disso, a adição de enzimas apropriadas é capaz de reduzir algumas das propriedades anti-nutricionais dos PNA's da parede celular (YIN et al., 2000), diminuir a variação da qualidade nutricional das dietas, permitir que a digestão aconteça mais rápida e completamente, diminuindo a excreção fecal de nutrientes e, conseqüentemente, a poluição ambiental, além de reduzir a incidência de fezes úmidas quando as aves são alimentadas com dietas de alta vicosidade (BEDFORD, 2000).

Este trabalho foi realizado com o objetivo de avaliar os efeitos da inclusão do farelo de trigo, com ou sem adição de um complexo enzimático, na ração de recria de poedeiras semipesadas e seus possíveis efeitos residuais na fase inicial de produção de ovos.

\section{MATERIAL E MÉTODOS}

O experimento foi conduzido no Laboratório Avícola do Centro de Formação de Tecnólogos (CFT) da Universidade Federal da Paraíba (UFPB). Foram utilizadas 288 poedeiras semipesadas da linhagem Lohmann Brown, com 15 semanas de idade e peso vivo inicial médio de $1,195 \pm 0,044 \mathrm{~kg}$.

Duas aves foram alojadas em gaiola de arame galvanizado ( $25 \mathrm{~cm} \mathrm{X} 45 \mathrm{~cm} \mathrm{X} 40 \mathrm{~cm}$ ). O galpão experimental $\left(75,6 \mathrm{~m}^{2}=2,8 \mathrm{~m} \mathrm{X} 27 \mathrm{~m}\right)$ possuia cobertura de telhas de barro em duas águas, pé-direito de $1,8 \mathrm{~m}$, duas fileiras de gaiolas sobrepostas e um corredor de $1 \mathrm{~m}$ de largura e orientação lesteoeste. As temperaturas máximas e mínimas (médias) registradas durante o período experimental foram de 33,22 e $22,04^{\circ} \mathrm{C}$, enquanto a umidade relativa do ar foi de 95,09 e 38,01\%, respectivamente, verificadas pela manhã ( $8 \mathrm{~h} 00)$ e à tarde (16h00).

$\mathrm{O}$ delineamento experimental utilizado foi $\mathrm{o}$ inteiramente ao acaso, em esquema fatorial $4 \times 2(0,10,20 \mathrm{e}$ $30 \%$ de farelo de trigo X 0 e $50 \mathrm{~g}$ de um complexo enzimático/ $100 \mathrm{~kg}$ de ração), totalizando oito tratamentos, com seis repetições de seis aves. O complexo enzimático (CE) comercial continha amilase, protease e celulase.

As rações de recria $\left(15^{\mathrm{a}}\right.$ a $19^{\mathrm{a}}$ semana de idade) foram isoenergéticas $(2.850 \mathrm{kcal} / \mathrm{kg})$ e isoprotéicas $(15,3 \%$ PB) e foram formuladas de acordo com Rostagno et al. (2000), conforme Tabela 1.

Para avaliar os efeitos residuais da inclusão do FT nas dietas das frangas de 15 a 19 semanas, sobre o início da produção de ovos. A partir da $20^{\mathrm{a}}$ semana as aves foram alimentadas com uma dieta convencional de postura $(2.700$ $\mathrm{kcal} / \mathrm{kg}, 15,95 \% \mathrm{~PB}, 4,1 \%$ de cálcio e $0,38 \%$ de fósforo disponível), isenta de FT, também formuladas de acordo com Rostagno et al. (2000) e as aves continuaram sendo observadas por dois períodos de 28 dias de produção de ovos. O balanço eletrolítico de 190,5 (ROSTAGNO et al., 2005) foi mantido constante por adição de cloreto de potássio. As aves receberam água e ração à vontade durante todo o período experimental e semanalmente, até completarem $50 \%$ de produção, todos os animais, sobras de ração e ovos, por parcela, foram pesados. 
Tabela 1 - Composições alimentar e nutricional das rações experimentais ${ }^{1}$.

\begin{tabular}{|c|c|c|c|c|}
\hline \multirow{2}{*}{ Ingredientes } & \multicolumn{4}{|c|}{ Níveis de Farelo de Trigo } \\
\hline & 0 & 10 & 20 & 30 \\
\hline Milho & 71,008 & 67,508 & 61,485 & 50,907 \\
\hline Farelo de soja & 20,138 & 17,012 & 14,377 & 12,632 \\
\hline Farelo de trigo & 0,000 & 10,000 & 20,000 & 30,000 \\
\hline Calcário & 0,894 & 0,960 & 1,019 & 1,068 \\
\hline Fosfato Bicálcio & 1,556 & 1,447 & 1,343 & 1,250 \\
\hline L-Lisina $\bullet \mathrm{HCl}$ & 0,019 & 0,068 & 0,108 & 0,131 \\
\hline DL-Metionina & 0,045 & 0,052 & 0,062 & 0,078 \\
\hline Óleo Vegetal & 0,000 & 0,000 & 0,841 & 3,200 \\
\hline Premix Vitamínico $^{2}$ & 0,080 & 0,080 & 0,080 & 0,080 \\
\hline Premix Mineral $^{3}$ & 0,050 & 0,050 & 0,050 & 0,050 \\
\hline Cloreto de Colina & 0,100 & 0,100 & 0,100 & 0,100 \\
\hline Antioxidante $^{4}$ & 0,010 & 0,010 & 0,010 & 0,010 \\
\hline $\mathrm{NaCl}$ (Sal Comum) & 0,099 & 0,119 & 0,146 & 0,176 \\
\hline Bicarbonato de Sódio & 0,318 & 0,289 & 0,239 & 0,197 \\
\hline Anticoccidiano & 0,040 & 0,040 & 0,040 & 0,040 \\
\hline Promotor de Crescimento & 0,010 & 0,010 & 0,010 & 0,010 \\
\hline Inerte $^{5}$ & 5,522 & 2,153 & 0,000 & 0,000 \\
\hline L-Treonina & 0,000 & 0,024 & 0,048 & 0,071 \\
\hline Cloreto de Potássio & 0,109 & 0,076 & 0,040 & 0,000 \\
\hline TOTAL & 100,000 & 100,000 & 100,000 & 100,000 \\
\hline Valores Calculados & \multicolumn{4}{|c|}{ Composição Química } \\
\hline Proteína Bruta & 15,300 & 15,300 & 15,300 & 15,300 \\
\hline $\mathrm{EM}, \mathrm{kcal} / \mathrm{kg}$ & 2.850 & 2.850 & 2.850 & 2.850 \\
\hline Metionina Digestível & 0,279 & 0,288 & 0,280 & 0,277 \\
\hline Metionina + Cistina Digestíveis & 0,500 & 0,500 & 0,500 & 0,500 \\
\hline Lisina Digestível & 0,668 & 0,668 & 0,668 & 0,668 \\
\hline Treonina Digestível & 0,510 & 0,510 & 0,510 & 0,512 \\
\hline Triptofano Digestível & 0,150 & 0,154 & 0,158 & 0,159 \\
\hline Cálcio & 0,815 & 0,815 & 0,815 & 0,815 \\
\hline Fósforo Disponível & 0,383 & 0,383 & 0,383 & 0,383 \\
\hline Sódio & 0,157 & 0,157 & 0,160 & 0,160 \\
\hline Potássio & 0,641 & 0,640 & 0,640 & 0,640 \\
\hline Cloro & 0,148 & 0,148 & 0,148 & 0,148 \\
\hline Fibra Bruta & 2,535 & 3,137 & 3,781 & 4,424 \\
\hline
\end{tabular}

${ }^{1}$ Recomendações de Rostagno et al. (2000).

${ }^{2}$ Composição por kg do produto. Vit. A 10.000 .000 UI; Vit. D 2.500 .000 UI; Vit. E 6.000 UI; Vit. K 1.600 mg; Vit. B 11.000 mcg; Niacina 25.000 mg; Ácido fólico 400 mg; Ácido pantotênico 10.000 mg; Selênio 300 mg; Veículo q. s. p.

${ }^{3}$ Composição por kg do produto. Manganês 150.000 mg; Zinco 100.000 mg; Ferro 100.000 mg; Cobre 16.000 mg; Iodo 1.500 mg; Veículo q. s. p. ${ }^{4}$ Antioxidante $=$ BHT $($ Beta-hidroxi-tolueno $)$.

${ }^{5}$ Inerte: areia lavada.

As variáveis estudadas na fase de recria foram: peso vivo final (PVF), ganho de peso (GP), consumo de ração (CR), conversão alimentar (CA), dias para postura do primeiro ovo (DIA), peso inicial do ovo (PIO) e dias transcorridos desde a postura do primeiro ovo até completar 50\% de produção (DP50\%). Na fase de produção, 
as variáveis estudadas foram: peso vivo inicial (PVI), consumo de ração (CR), produção (PR), peso do ovo (PO), massa de ovos (MO), conversão por massa (CMO), conversão por dúzia (CDZ) de ovos e gravidade específica (GE) dos ovos.

O GP foi calculado pela diferença entre o peso final e 0 inicial e o consumo alimentar pela diferença entre a quantidade da ração fornecida e as sobras obtidas dos comedouros e baldes. A postura do $1^{\circ}$ ovo foi acompanhada para a obtenção da idade das aves ao $1^{\circ}$ ovo, acompanhamento que perdurou até atingirem $50 \%$ de produção ( 6 aves produzindo 3 ovos), onde foi obtido o tempo em dias para as aves atingirem esse porcentual de produção. Nesse período, também foram pesados todos os ovos para a obtenção do peso do $1^{\circ}$ ovo.

A coleta de dados da fase de produção foi iniciada quando as aves do experimento atingiram $50 \%$ de produção (288 aves produzindo 144 ovos), o que ocorreu quando as aves completaram a $24^{\mathrm{a}}$ semana de idade, e elas foram pesadas para obtenção do peso vivo inicial da fase de produção. Portanto, o peso vivo final das aves na fase de recria, obtidos na $19^{\mathrm{a}}$ semana, é distinto do peso vivo inicial da fase de produção.

A produção de ovos foi obtida em porcentagem/ave/ dia. O peso dos ovos foi o valor médio do peso dos ovos produzidos nos últimos cinco dias de cada fase experimental. A massa de ovos representou o produto da porcentagem de ovos produzida pelo peso médio dos ovos, enquanto a conversão alimentar por massa de ovos foi expressa em quilos de ração por quilo de massa de ovos produzida e a conversão alimentar por dúzia de ovos foi a relação entre a quantidade de ração consumida $(\mathrm{kg})$ por dúzia de ovos produzida.
A gravidade específica foi determinada pelo método da flutuação dos ovos em quinze soluções salinas, com variação da densidade em 0,0025 unidades, iniciando por 1,0625 até 1,100 . Para tal, foram utilizados quinze baldes com capacidade de 50 litros, um densímetro de petróleo com escala de 1,050 a 1,100, uma cesta de plástico (balde vazado), água e sal comum, sempre nos últimos três dias de cada fase experimental. As aves mortas e as sobras das dietas foram consideradas para ajustar o consumo, a produção de ovos e as conversões alimentares.

As análises estatísticas foram realizadas através do programa SAEG, desenvolvido pela Universidade Federal de Viçosa - UFV (1983). Após a análise de variância, o efeito dos níveis de FT e do CE sobre os resultados das variáveis foram avaliados pelo teste Student-NewmanKeuls $(\mathrm{P} \leq 0,05)$. Posteriormente, as somas de quadrado dos efeitos do FT foram decompostas nos efeitos lineares, quadráticos e cúbicos, e na escolha dos modelos de regressões foram considerados o nível de significância, o coeficiente de determinação $\left(\mathrm{r}^{2}\right)$ e a resposta biológica das aves.

\section{RESULTADOS E DISCUSSÃO}

\section{Fase de Recria}

Os resultados referentes ao GP, CA, CR e PVF, na fase de crescimento, em função dos diferentes níveis de inclusão do FT e adição ou não do CE nas dietas experimentais são apresentados na Tabela 2.

Tabela 2 - Ganho de peso (GP), conversão alimentar (CA), consumo de ração (CR) e peso vivo final (PVF) em função dos níveis de farelo de trigo (FT) e do complexo enzimático (CE).

\begin{tabular}{|c|c|c|c|c|c|c|}
\hline & \multirow{3}{*}{ GP, g/ave/dia } & \multirow{3}{*}{$\mathrm{CA}$} & \multicolumn{2}{|c|}{ CR, g/ave/dia } & \multicolumn{2}{|c|}{ PVF, kg } \\
\hline & & & \multicolumn{2}{|c|}{$\mathrm{CE}$} & \multicolumn{2}{|c|}{$\mathrm{CE}$} \\
\hline FT, \% & & & 0 & 0,05 & 0 & 0,05 \\
\hline 0 & $12,32^{\mathrm{A}}$ & $6,89^{\mathrm{B}}$ & $84,91^{\mathrm{a}}$ & $81,64^{\mathrm{b}}$ & 1,483 & 1,506 \\
\hline 10 & $10,65^{\mathrm{B}}$ & $7,03^{\mathrm{B}}$ & 74,88 & 73,91 & $1,437^{\mathrm{a}}$ & $1,409^{b}$ \\
\hline 20 & $9,98^{\mathrm{B}}$ & $6,78^{\mathrm{B}}$ & 67,66 & 69,00 & 1,364 & 1,378 \\
\hline 30 & $6,44^{\mathrm{C}}$ & $9,71^{\mathrm{A}}$ & $62,53^{\mathrm{a}}$ & $57,99^{\mathrm{b}}$ & $1,294^{\mathrm{a}}$ & $1,248^{\mathrm{b}}$ \\
\hline \multicolumn{7}{|l|}{$\mathrm{CE}$} \\
\hline 0,00 & 9,68 & 7,67 & - & - & - & - \\
\hline 0,05 & 10,02 & 7,43 & - & - & - & - \\
\hline \multicolumn{7}{|l|}{ Anova } \\
\hline Linear & $* *$ & $* *$ & $* *$ & $* *$ & $* *$ & $* *$ \\
\hline Quadrático & $* *$ & $* *$ & $* *$ & $*$ & ns & ns \\
\hline $\mathrm{CV} \%$ & 8,938 & 1,632 & \multicolumn{2}{|c|}{2,727} & \multicolumn{2}{|c|}{1,632} \\
\hline
\end{tabular}

Ciênc. agrotec., Lavras, v. 32, n. 6, p. 1960-1967, nov./dez., 2008 
O ganho de peso e a conversão alimentar foram afetados linearmente $(\mathrm{P} \leq 0,01)$ pelos níveis crescentes de FT na ração, de modo que o ganho de peso diminuiu ( $\left.\hat{y}=12,596-0,182971 X ; r^{2}=0,91\right)$, enquanto a conversão alimentar piorou $\left(\hat{y}=6,35179+0,0802109 X ; r^{2}=0,62\right)$ à medida que a proporção de FT foi elevada na ração. $\mathrm{O}$ aumento em cerca de $40 \%$ do teor de fibra bruta, da ração basal para a ração com $30 \%$ de FT, pode ter afetado negativamente a utilização dos nutrientes, em virtude da fibra atuar como uma "barreira", impedindo que as proteases tenham acesso aos locais nas células vegetais onde estão depositados os aminoácidos. Araujo et al. (2005, 2008a) trabalhando com frangas de reposição de 7 a 14 semanas, também observaram comportamento semelhante, com a diminuição do ganho de peso em cerca de $0,03 \mathrm{~g}$ e do peso vivo final em $1,15 \mathrm{~g}$, para cada aumento de $1 \%$ na inclusão do FT, na ração.

Embora os níveis de 10 e $20 \%$ de inclusão do FT não tenham diferido do controle $(\mathrm{P}>0,05)$, quando o FT foi incluído em $30 \%$ na ração, a conversão alimentar piorou significativamente. Braga et al. (2005) avaliaram o desempenho de poedeiras em produção, alimentadas com rações contendo níveis crescentes de farelo de coco $(0,5$, 10,15 e $20 \%$ ), o que também aumentou o porcentual de fibra da dieta de 2,08 para 4,5\% (mais de $100 \%$ ), encontrando resultados que contradizem os observados no presente trabalho. Esses autores afirmaram que apenas o consumo das aves que receberam rações com $20 \%$ de farelo de coco foi significativamente reduzido. Embora a produção e a massa de ovos tenham piorado em valores absolutos, não houve efeito significativo para essas variáveis. No entanto, os autores recomendaram cautela na utilização de alimentos que deprimam o consumo de ração das aves, em virtude dos impactos negativos sobre o desempenho.

Houve efeito de interação $(\mathrm{P} \leq 0,05)$ entre o FT e o CE para o consumo de ração e o peso vivo final. O consumo de ração diminuiu linearmente na ausência ( $\hat{y}=83,6478$ $\left.0,743515 X ; r^{2}=0,98\right)$ ou na presença $(\hat{y}=82,0195-0,758667 X$ $\left.\mathrm{r}^{2}=0,98\right)$ do CE na ração. Da mesma forma, o peso vivo final foi reduzido em 6,46 e $8,06 \mathrm{~g}$ por cada $1 \%$ de inclusão do FT na ração, de acordo com as equações: $\hat{y}=1491,51$ $6,46146 \mathrm{X} ; \mathrm{r}^{2}=0,99$ e $\hat{\mathrm{y}}=1506,84-8,06597 \mathrm{X} ; \mathrm{r}^{2}=0,95$; respectivamente, com e sem adição do $\mathrm{CE}$ à ração. $\mathrm{A}$ suplementação da dieta controle e daquela com $30 \%$ de FT com o CE reduziu o consumo significativamente $(\mathrm{P} \leq 0,05)$. O peso vivo final também foi reduzido significativamente $(\mathrm{P} \leq 0,05)$ com a suplementação das rações com 10 e $30 \%$ de FT com o CE.

O pior desempenho das frangas alimentadas com os níveis mais altos de FT pode estar relacionado ao aumento crescente da fibra bruta da ração. Segundo Maes et al. (2004), a fibra do FT é composta por 9,1\% de arabinose e
$15,2 \%$ de xilose (21,4\% de arabinoxilans). Além disso, a fibra do FT consiste de componentes estruturais, como celulose e lignina (SCHOONEVELD-BERGMANS et al., 1999), que não são digeridos, não fornecendo energia às aves. De acordo com Boros et al. (2002) as arabinoxilans não são apenas inertes à ação das enzimas endógenas das aves, mas também interferem na digestão e absorção de todos os nutrientes, pelas suas propriedades de aumentar a viscosidade intestinal. Esses efeitos dos PNA's solúveis podem ser mais pronunciados quanto mais jovens forem as aves; o que coincide com o período avaliado neste estudo, no qual as poedeiras ainda não haviam atingido a idade adulta.

Os resultados referentes aos dias para postura do primeiro ovo, PIO e dias transcorridos desde a postura do primeiro ovo até completar $50 \%$ de produção (DP50\%), encontram-se na Tabela 3.

A idade das aves ao primeiro ovo aumentou significativamente $(\mathrm{P} \leq 0,05)$ quando se adicionaram níveis crescentes de FT na ração, de acordo com a equação $\hat{y}=135,3+0,484167 X ; r^{2}=0,95$. Para o peso inicial do ovo, houve tendência de aumento com os crescentes níveis de FT, entretanto não houve efeito significativo $(\mathrm{P}>0,05)$. Araujo et al. (2005, 2008a), trabalhando com poedeiras alimentadas com rações contendo níveis crescentes de inclusão de FT (0 a 30\%) das 7 às 19 semanas de idade, comprovaram o efeito residual do FT em retardar o início da postura e aumentar o peso inicial dos ovos, resultados que corroboram com os do presente estudo. O total de dias transcorridos desde a postura do primeiro ovo até completar $50 \%$ de produção, também foi aumentado de forma linear com a inclusão do FT, mas também não houve efeito significativo $(\mathrm{P}>0,05)$. Idade ao primeiro ovo, peso inicial do ovo e dias transcorridos desde a postura do primeiro ovo até completar $50 \%$ de produção não foram afetados pela adição do CE e não houve efeito de interação entre FT e CE, para nenhuma dessas variáveis.

\section{Fase de Produção}

Para a fase de postura, considerando os efeitos principais, observou-se que o consumo de ração, peso do ovo e a gravidade específica dos ovos não foram afetados pela adição do FT e o CE não teve efeito significativo sobre os resultados de nenhuma das variáveis estudadas.

O consumo de ração, peso e massa de ovos, conversão por massa e por dúzia de ovos, gravidade específica e produção de ovos, peso vivo inicial de poedeiras semipesadas, na fase de produção, em função dos níveis de farelo de trigo e da inclusão ou não do complexo enzimático, encontram-se na tabela 4. 
Tabela 3 - Dias para postura do primeiro ovo (DIA), peso inicial do ovo (PIO) e dias transcorridos desde a postura do primeiro ovo até completar 50\% de produção (DP50\%) em função dos níveis de farelo de trigo (FT) e do complexo enzimático (CE).

\begin{tabular}{|c|c|c|c|}
\hline & DIA, dias & PIO, g & DP50\%, dias \\
\hline \multicolumn{4}{|l|}{ FT, \% } \\
\hline 0 & $134,2^{\mathrm{c}}$ & 42,87 & 6,83 \\
\hline 10 & $140,9^{\mathrm{b}}$ & 43,11 & 6,75 \\
\hline 20 & $146,6^{\mathrm{a}}$ & 42,29 & 8,67 \\
\hline 30 & $148,5^{\mathrm{a}}$ & 45,54 & 9,00 \\
\hline \multicolumn{4}{|l|}{$\mathrm{CE}$} \\
\hline 0,00 & 141,25 & 44,72 & 7,96 \\
\hline 0,05 & 143,88 & 42,19 & 7,67 \\
\hline \multicolumn{4}{|l|}{ Anova } \\
\hline FT & $* * \mathrm{~L}$ & ns & ns \\
\hline $\mathrm{CE}$ & ns & $\mathrm{ns}$ & $\mathrm{ns}$ \\
\hline FT X CE & ns & ns & $\mathrm{ns}$ \\
\hline $\mathrm{CV} \%$ & 3,895 & 3,451 & 75,042 \\
\hline
\end{tabular}

Tabela 4 - Consumo de ração, g/ave/dia (CR); peso do ovo, g (PO); massa de ovos, g (MO); conversão por massa de ovos, $\mathrm{kg} / \mathrm{kg}(\mathrm{CMO})$; conversão por dúzia de ovos, $\mathrm{kg} /$ dúzia (CDZ), gravidade específica, g/cm³ (GE); peso vivo inicial, kg (PVI) e produção de ovos, \% (PR) em função dos níveis de farelo de trigo (FT) e do complexo enzimático (CE) na fase de produção.

\begin{tabular}{|c|c|c|c|c|c|c|c|c|c|c|}
\hline & \multirow{2}{*}{$\mathrm{CR}$} & \multirow{2}{*}{$\mathrm{PO}$} & \multirow{2}{*}{ MO } & \multirow{2}{*}{$\mathrm{CMO}$} & \multirow{2}{*}{$\mathrm{CDZ}$} & \multirow{2}{*}{ GE } & \multicolumn{2}{|c|}{ PVI } & \multicolumn{2}{|c|}{ PR } \\
\hline & & & & & & & \multicolumn{2}{|c|}{$\mathrm{CE}$} & \multicolumn{2}{|c|}{$\mathrm{CE}$} \\
\hline FT, \% & & & & & & & 0 & 0,05 & 0 & 0,05 \\
\hline 0 & 150,80 & 59,14 & 44,28 & $3,40^{\mathrm{B}}$ & $2,11^{\mathrm{C}}$ & 1,0878 & $1,706^{\mathrm{b}}$ & $1,770^{\mathrm{a}}$ & 82,57 & 80,60 \\
\hline 10 & 145,76 & 59,28 & 43,94 & $3,31^{\mathrm{B}}$ & $2,20^{\mathrm{BC}}$ & 1,0881 & 1,719 & 1,747 & 79,74 & 81,28 \\
\hline 20 & 151,30 & 60,45 & 43,41 & $3,48^{\mathrm{B}}$ & $2,29^{\mathrm{B}}$ & 1,0874 & 1,720 & 1,713 & $83,19^{\mathrm{a}}$ & $72,87^{\mathrm{b}}$ \\
\hline 30 & 150,84 & 59,28 & 40,03 & $3,77^{\mathrm{A}}$ & $2,46^{\mathrm{A}}$ & 1,0876 & $1,654^{\mathrm{a}}$ & $1,600^{\mathrm{b}}$ & 73,88 & 72.80 \\
\hline \multicolumn{11}{|l|}{$\mathrm{CE}$} \\
\hline 0,00 & 149,06 & 59,22 & 43,51 & 3,42 & 2,27 & 1,0881 & - & - & - & - \\
\hline 0,05 & 150,30 & 59,85 & 42,32 & 3,55 & 2,26 & 1,0873 & - & - & - & - \\
\hline \multicolumn{11}{|l|}{ Anova } \\
\hline Linear & ns & $\mathrm{ns}$ & $* *$ & $* *$ & $* *$ & ns & $*$ & $* *$ & $* *$ & $* *$ \\
\hline Quadrático & ns & ns & Ns & $*$ & ns & ns & $*$ & $* *$ & $\mathrm{~ns}$ & ns \\
\hline CV\% & 5,257 & 4,536 & 7,834 & 8,190 & 5,957 & 7,876 & \multicolumn{2}{|c|}{2,327} & \multicolumn{2}{|c|}{6,667} \\
\hline
\end{tabular}

${ }_{\mathrm{a}, \mathrm{b}}$ Médias nas linhas seguidas de letras minúsculas distintas, são diferentes pelo teste SNK $(\mathrm{P} \leq 0,05)$.

${ }^{\mathrm{AB}}$ Médias nas colunas seguidas de letras maiúsculas distintas, são diferentes pelo teste $\mathrm{SNK}(\mathrm{P} \leq 0,05)$. ns $=$ Não Significativo. ${ }^{*}(\mathrm{P} \leq 0,05) ;{ }^{\star \star}(\mathrm{P} \leq 0,01)$.

Freitas et al. (2000) estudando a resposta de poedeiras alimentadas com rações à base de milho, de farelo de soja e de até $6 \%$ de farelo de trigo, formuladas com 2850 e $2750 \mathrm{kcal} \mathrm{EM} / \mathrm{kg}$ com e sem adição de um CE (alfa-amilase, xilanase e protease), também não verificaram efeito da suplementação das rações com o CE sobre o desempenho 
das aves. Esses autores atribuíram o fato à redução insuficiente da energia (de 2850 para $2750 \mathrm{kcal} \mathrm{EM} / \mathrm{kg}$ ) entre as dietas, para que fossem constatados os efeitos da adição do CE.

Para as aves que receberam dietas com até $20 \%$ de FT durante a fase de recria, o peso vivo inicial da fase de postura não diferiu do tratamento controle, entretanto foi observado efeito $(\mathrm{P} \leq 0,01)$ residual do tratamento que continha $30 \%$ de FT, que foi inferior ao peso das frangas do controle. Pucci et al. (2003) estudando os efeitos de diferentes níveis de óleo com ou sem adição de um complexo enzimático contendo xilanase, amilase e protease sobre o desempenho de frangos de corte de 1 a 42 dias, não observaram efeito $(\mathrm{P} \leq 0,05)$ da adição do complexo sobre o consumo de ração e ganho de peso das aves. Entretanto, Conte et al. (2003) utilizaram xilanase e fitase em dietas contendo farelo de arroz, ingrediente tão rico quanto o farelo de trigo em PNA's, principalmente arabinoxilans, para frangos de corte de 1 a 42 dias e constataram que a utilização da enzima xilanase não afetou de maneira significativa $(\mathrm{P}>0,05)$ o peso vivo e o consumo de ração, mas observou-se melhor conversão alimentar $(\mathrm{P} \leq 0,05)$, o que, de acordo com os autores confirma a sua ação sobre a digestibilidade de nutrientes, principalmente no aumento da energia metabolizável.

A massa de ovos foi reduzida de forma linear em $0,13 \mathrm{~g}$ para cada $1 \%$ de aumento do FT na dieta $\hat{y}=44,9065-0,132645 \mathrm{X}$ $\left.\mathrm{r}^{2}=0,77\right)$ e a conversão por massa de ovos apresentou comportamento quadrático em função do nível crescente do FT na ração, com nível ótimo de 8,01\% de inclusão do FT $\left(\hat{y}=3,41107-0,0147473 X+0,000920176 X^{2} ; r^{2}=0,99\right)$. A conversão alimentar por dúzia de ovos piorou linearmente ( $\hat{y}=2,09507+0,0115215 X ; r^{2}=0,97$ ), pelo efeito residual relacionado ao aumento do nível de FT na ração de recria.

Houve interação entre os níveis de FT das rações de recria e a adição do CE para o peso vivo inicial e para a produção. $\mathrm{O}$ peso vivo inicial decresceu linearmente $(\mathrm{P} \leq 0,05)$ com o aumento do nível de FT, na ausência $\left(1723,83-1,5750 X ; r^{2}=0,42\right)$ ou presença $(Y=1789,86$ $\left.5,45833 \mathrm{X} ; \mathrm{r}^{2}=0,87\right)$ do $\mathrm{CE}$ nas rações de recria. A produção de ovos também decresceu linearmente $(\mathrm{P} \leq 0,05)$ com o aumento do nível de FT, na ausência ( $\mathrm{Y}=83,2296-0,227252 \mathrm{X}$; $\left.r^{2}=0,48\right)$ ou presença $\left(Y=81,6585-0,317947 X ; r^{2}=0,77\right)$ do $C E$ nas rações de recria. Para as aves que haviam recebido dietas à base de milho e de farelo de soja, a adição do complexo enzimático melhorou o peso vivo inicial $(\mathrm{P} \leq 0,01)$, que aumentou de $1.706,94$ para $1.770,83 \mathrm{~g}$, enquanto que para as aves que haviam recebido $30 \%$ de FT, o peso vivo inicial diminuiu de $1.654,17$ para $1.600,00 \mathrm{~g}$. A produção foi piorada $(\mathrm{P} \leq 0,01)$, com $20 \%$ de inclusão do FT na ração suplementada com o CE, passando de 83,19 para $72,80 \%$.

\section{CONCLUSÃO}

A inclusão de até $30 \%$ de farelo de trigo na ração de recria compromete o crescimento até as 19 semanas de idade, retarda a postura do primeiro ovo e afeta o desempenho de galinhas até o final do pique de postura. Com base na conversão alimentar por massa de ovos, recomenda-se até $8,01 \%$ de FT na dieta de poedeiras de 15 a 19 semanas de idade. A adição de $50 \mathrm{~g} / 100 \mathrm{~kg}$ de ração do complexo enzimático (amilase, protease e celulase), nas rações de recria, não melhora o desempenho de frangas semipesadas.

\section{REFERÊNCIAS BIBLIOGRÁFICAS}

ARAUJO, D. M.; SILVA, J. H. V.; ARAUJO, J. A. Inclusão do farelo de trigo na alimentação de poedeiras semipesadas durante a recria. Revista Brasileira de Ciência Avícola, v. 7, p. 136, 2005. Suplemento.

ARAUJO, D. M.; SILVA, J. H. V.; ARAUJO, J. A. Farelo de trigo na alimentação de poedeiras semipesadas na fase de recria. Revista Brasileira de Zootecnia, Viçosa, v. 37, n. 1, p. 67-72, 2008a.

ARAUJO, D. M.; SILVA, J. H. V.; MIRANDA, E. C. Farelo de trigo e complexo enzimático na alimentação de poedeiras semipesadas na fase de produção. Revista Brasileira de Zootecnia, Viçosa, v. 37, n. 5, p. 843-848, 2008b.

BEAUGRAND, J.; CRÔNIER, D.; DEBEIRE, P.; CHABBERT, B. Arabinoxylan and hydroxycinnamate content of wheat bran in relation to endoxylanase susceptibility. Journal of Cereal Science, v. 40, p. 223-230, 2004.

BEDFORD, M. R. Exogenous enzymes in monogastric nutrition: their current value and future benefits. Animal Feed Science and Technology, v. 86, p. 1-13, 2000.

BEDFORD, M. R.; PARTRIDGE, G. G. Enzymes in farm animal nutrition. Marlborough: CABI, 2001. 432 p.

BOROS, D.; MARQUARDT, R. R.; GUENTER, W.; BRUFAU, J. Chick adaptation to diets based on milling fractions of rye varying in arabinoxylans content. Animal Feed Science and Technology, v. 101, p. 135-149, 2002.

BRAGA, C. V. P.; FUENTES, M. F. F.; FREITAS, E. R.; CARVALHO, L. E.; SOUSA, F. M.; BASTOS, S. C. Efeito da inclusão do farelo de coco em rações para poedeiras comerciais. Revista Brasileira de Zootecnia, Viçosa, v. 34, n. 1, p. 76-80, 2005. 
CONTE, A. J.; TEIXEIRA, A. S.; FIALHO, E. T.; SCHOULTEN, N. A.; BERTECHINI, A. G. Efeito da fitase e xilanase sobre o desempenho e as características ósseas de frangos de corte alimentados com dietas contendo farelo de arroz. Revista Brasileira de Zootecnia, Viçosa, v. 32, n. 5, p. 1147-1156, 2003.

EVERS, T.; MILLAR, S. Cereal grain structure and development: some implications for quality. Journal of Cereal Science, v. 36, p. 261-284, 2002.

FREITAS, E. R.; FUENTES, M. F. F.; ESPÍNDOLA, G. B. Efeito da suplementação enzimática em rações à base de milho/farelo de soja sobre o desempenho de poedeiras comerciais. Revista Brasileira de Zootecnia, Viçosa, v. 29, n. 4, p. 1103-1109, 2000.

HELSBY, N.A.; ZHUA, S.; PEARSON,A. E. Antimutagenic effects of wheat bran diet through modification of xenobiotic metabolising enzymes. Mutation Research, v. 454, p. 77-88, 2000.

MAES, C.; VANGENEUGDEN, B.; DELCOUR, J. A. Relative activity of two endoxylanases towards waterunextractable arabinoxylans in wheat bran. Journal of Cereal Science, v. 39, p. 181-186, 2004.

MONTAGNE, L.; PLUSKE, J. R.; HAMPSON, D. J. A review of interactions between dietary fibre and the intestinal mucosa, and their consequences on digestive health in young non-ruminant animals. Animal Feed Science and Technology, v. 108, p. 95-117, 2003.

PUCCI, L. E. A.; RODRIGUES, P. B.; FREITAS, R. T. F.; BERTECHINI, A. G.; CARVALHO, E. M. Níveis de óleo e adição de complexo enzimático na ração de frangos de corte. Revista Brasileira de Zootecnia, Viçosa, v. 32, n. 4, p. $909-917,2003$.

ROSTAGNO, H. S.; ALBINO, L. F. T.; DONZELE, J. L. Tabelas brasileiras para suínos e aves: composição de alimentos e exigências nutricionais. Viçosa: UFV, 2000. 141 p.

ROSTAGNO, H. S.; ALBINO, L. F. T.; DONZELE, J. L. Tabelas brasileiras para suínos e aves: composição de alimentos e exigências nutricionais. 2. ed. Viçosa: UFV, $2005.186 \mathrm{p}$.

SCHOONEVELD-BERGMANS, M. E. F.; BELDMAN, G; VORAGEN, A. G. J. Structural features of (glucurono) arabinoxylans extracted from wheat bran by barium hydroxide. Journal of Cereal Science, v. 29, p. 63-75, 1999.

SILVA, J. H. V.; OLIVEIRA, J. N. C.; SILVA, E. L.; JUNQUEIRA FILHO, J.; RIBEIRO, M. L. G. Uso da farinha integral da vagem de algaroba (Prosopis juliflora (Sw.) D.C.) na alimentação de codornas japonesas. Revista Brasileira de Zootecnia, Viçosa, v. 31, n. 4, p. 1789-1794, 2002.

UNIVERSIDADE FEDERAL DE VIÇOSA. SAEG (Sistema de Análises Estatísticas e Genéticas). Versão 5.0. Viçosa, MG, 1983. 69 p. Manual do usuário.

YIN, Y. L.; MCEVOY, J. D. G.; SCHULZE, H. Apparent digestibility (ileal and overall) of nutrients and endogenous nitrogen losses in growing pigs fed wheat (var. Soissons) or its by-products without or with xylanase supplementation. Livestock Production Science, v. 62, p. $119-132,2000$. 